\title{
The c-Jun N-terminal kinase JNK participates in cytokine- and isolation stress-induced rat pancreatic islet apoptosis
}

\author{
S. Abdelli • A. Abderrahmani • B. J. Hering • \\ J. S. Beckmann • C. Bonny
}

Received: 17 November 2006 / Accepted: 9 March 2007 / Published online: 9 June 2007

(C) Springer-Verlag 2007

\begin{abstract}
Aims/hypothesis The protocols used for the preparation of human pancreatic islets immediately induce a sustained and massive activation of the c-Jun-N-terminal kinase (JNK). $\mathrm{JNK}$, which participates in apoptosis of insulin-secreting cells, is activated by mechanical stresses, as well as by exposure to pro-inflammatory cytokines. Here, we investigated whether the delivery of a protease-resistant JNK inhibitory peptide (D-JNKI) through a protein transduction system during pancreatic digestion might impair JNK signalling throughout the transplantation procedure.

Methods Rat pancreases were treated with D-JNKI through the pancreatic duct and cells then isolated by enzymatic digestion. Protein extracts were prepared to determine JNK activity by kinase assays and total RNA was extracted to measure gene expressions by a Light-Cycler technique. Cell apoptosis rate was determined by terminal deoxynucleotidyl transferase dUTP nick end labelling (TUNEL) assay and by scoring cells displaying pycnotic nuclei.
\end{abstract}

S. Abdelli · J. S. Beckmann · C. Bonny $(\bowtie)$

Service of Medical Genetics, CHUV Hospital,

Chemin des Falaises 1,

1011 Lausanne-CHUV, Switzerland

e-mail: Christophe.Bonny@chuv.ch

C. Bonny

e-mail: cb@xigenpharma.com

S. Abdelli $\cdot$ A. Abderrahmani

Department of Cellular Biology and Morphology,

University of Lausanne,

Lausanne, Switzerland

B. J Hering

Diabetes Institute for Immunology and Transplantation,

University of Minnesota,

Minneapolis, MN, USA
Results Our data establish that the peptide transduction system used here efficiently transfects islets, allowing for stable in vivo (up to 2 days) transfection of human islets transplanted under the kidney capsule. Further, D-JNKI decreases intracellular JNK signalling during isolation and following cytokine exposure in both human and rat islets, as measured by kinase assays and reduced c-fos expression; D-JNKI also confers protection against apoptosis induced during the rat islet preparation and subsequent to IL-1 $\beta$ exposure.

Conclusions/interpretation JNK signalling participates in islet isolation- and IL-1 $\beta$-induced apoptosis in rat islets. Furthermore, the system we used might be more generally applicable for the persistent blockage (several days) of proapoptotic pathways in the transplanted islets; this days-long protection might potentially be an absolute prerequisite to help transplanted islets better survive the first wave of the non-specific inflammatory attack.

Keywords Apoptosis · Cytokines · D-JNKI · Islet · Isolation $\cdot \mathrm{JNK} \cdot$ Transplantation
Abbreviations
D-JNKI protease-resistant JNK inhibitory peptide
D-TAT-FITC fluorescein isothiocyanate-labelled D-TAT transporter
DTT dithiothreitol
FIM functional islet mass
GST glutathione $S$-transferase
HIV human immunodeficiency virus
IB1 islet brain-1
JNK c-Jun-N-terminal kinase
NF- $k$ B nuclear factor-kappaB 
TUNEL terminal deoxynucleotidyl transferase dUTP nick end labelling

\section{Introduction}

It is estimated that up to $60 \%$ of pancreatic islet tissue undergoes apoptosis within a few days after transplantation, suggesting that non-specific inflammatory events play a key role in the destruction of the graft after transplantation [1]. The pro-inflammatory cytokines IL- $1 \beta$, TNF- $\alpha$ and IFN- $\gamma$ participate in the functional impairment and destruction of beta cells during type 1 diabetes mellitus [2], and are also at least in part responsible for the observed loss of functional islet mass (FIM) following grafting [3]. Amongst the three cytokines, IL-1 $\beta$ is the most important inflammatory mediator that causes pancreatic islet dysfunction and destruction [4]. IL-1 $\beta$ alone is sufficient to induce apoptosis of pancreatic beta cells in both rat and mouse pancreatic islets, while addition of IFN- $\gamma$ to IL- $1 \beta$ is required to trigger apoptosis of human pancreatic islets [5]. In beta cell lines, IL-1 $\beta$ acts mostly by increasing the activity of two main pathways: the c-Jun N-terminal kinase (JNK, also known as mitogen-activated protein kinase 8) [6], and translocation of nuclear factor-kappaB (NF-kB) [7]. In addition to cytokine stimulation, stress conditions such as the islet isolation procedure itself also decrease the viability of pancreatic islets and alter their function with a major loss occurring shortly after the final purification steps [8].

Both effects, stress conditions during isolation and nonspecific inflammatory events following transplantation, then combine to strongly impair viability of islets. Consequently, a high number of islets from multiple donors are required to perform islet grafting [9], and therefore islet shortage and early loss of FIM are the main limitations to the expansion of islet transplantation as a curative therapy for type 1 diabetes mellitus [10].

We have previously shown that the isolation procedure extremely potently activates the JNK signalling pathway for a period of time starting from the earliest steps of isolation up to several hours following purification (i.e. 6-8 h of activation); the same pathway is also activated by pro-inflammatory cytokines [11]. We here investigated whether the delivery of a protease-resistant JNK inhibitory peptide (D-JNKI) via a protein transduction system can improve viability of rat pancreatic islets following isolation or cytokine exposure.

\section{Materials and methods}

Isolation and culture of rat islets Pancreases from Sprague-Dawley male rats (Elevage Janvier, Le Genest Saint Isle, France) weighing $300 \mathrm{~g}$ were distended by intraductal injection of collagenase solution $(10 \mathrm{mg} / \mathrm{ml}$ in $10 \mathrm{ml}$ final volume; Worthington Biochemical, Lakewood, $\mathrm{NJ}$, USA) and digestion was performed in a water bath at $37^{\circ} \mathrm{C}$ for $30 \mathrm{~min}$ with gentle shaking. Fragmented tissue was washed, collected by centrifugation and islets were separated on Ficoll (Sigma Aldrich, San Diego, CA, USA) density gradients. The isolated islets treated with D-JNKI $(1 \mu \mathrm{mol} / \mathrm{l})$ (Auspep, Parkville, VIC, Australia) or not were cultured in 1640 medium (Gibco BRL Life Technologies, Miami, FL, USA) supplemented with $10 \%$ ( $\mathrm{vol} / \mathrm{vol})$ fetal calf serum, penicillin (100 U/ml) (Gibco BRL Life Technologies) and streptomycin $(100 \mu \mathrm{g} / \mathrm{ml})$ (Gibco BRL Life Technologies) in a $5 \% \mathrm{CO}_{2}$ humidified atmosphere at $37^{\circ} \mathrm{C}$. Cultured islets were exposed to recombinant mouse IL-1 $\beta$ (280 U/ng, Sigma Aldrich) at a concentration of $10 \mathrm{ng} / \mathrm{ml}$ for $45 \mathrm{~min}$. Animal experimentation conformed to the Guide for the Care and Use of Laboratory Animals, formulated by the National Research Council, 1996, and Swiss law on animal protection, and was authorised by the Veterinarian Office of Canton de Vaud (Lausanne, Switzerland).

Isolation and culture of human islets Human islet isolation was performed as described previously [11], using the method of Ricordi et al., which combines enzymatic digestion and mechanical dissociation [12]. Briefly, the pancreas was distended after injection of $350 \mathrm{ml}$ of an enzyme solution (Liberase-HI, reconstituted to a final volume of $350 \mathrm{ml}$ in HBSS; Roche Molecular Biochemicals, Indianapolis, IN, USA) into the main pancreatic duct, cut into several pieces and put in a temperature-controlled chamber. The digested pancreatic cells were collected by centrifugation and washed before density gradient purification. Purified islets, treated or not with D-JNKI $(10 \mu \mathrm{mol} / \mathrm{l})$, were cultured in CMRL-1066 medium supplemented with $10 \%$ (vol/vol) fetal bovine serum (Mediatech, Herndon, VA, USA) in a $5 \% \mathrm{CO}_{2}$ humidified atmosphere at $37^{\circ} \mathrm{C}$. Islets were then exposed for $45 \mathrm{~min}$ to recombinant human IL-1 $\beta$ at a concentration

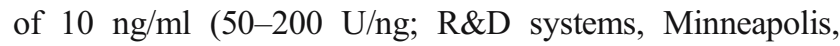
$\mathrm{MN}, \mathrm{USA})$. Isolated rat and human islets were washed with PBS, then collected by centrifugation and used for protein and RNA extraction. The human participants' exemption code from the institutional review board is 0307M50821.

Transduction of the islets with fluorescein isothiocyanate (FITC)labelled D-TAT transporter (D-TAT-FITC) peptide D-TATFITC transporter peptide (Auspep) at a concentration of $1 \mu \mathrm{mol} / 1$ (in $10 \mathrm{ml}$ cold sterile HBSS containing $10 \mathrm{mg} / \mathrm{ml}$ of collagenase) was injected into the rat pancreatic duct prior to enzymatic digestion and isolated islets were plated in culture medium at $37^{\circ} \mathrm{C}$. The presence of fluorescent peptide in the islets was assessed by confocal microscopy (Zeiss confocal laser scanning microscopy; Leica Confocal software) at different time-points. 
Islet transplantation under the renal capsule of nude mice Human islets were incubated for $1 \mathrm{~h}$ with or without D-TAT-FITC $(1 \mu \mathrm{mol} / \mathrm{l})$ peptide at $37^{\circ} \mathrm{C}$. Nude mice were anaesthetised by i.p. injection of pentobarbital and a small incision was made in the body wall in order to exteriorise the kidney. An incision in the capsule creates a pocket between capsule and kidney parenchyma. The islet graft was inserted into the pocket under the capsule. When grafting was completed, the kidney was eased back into the body and the back of the skin was closed. Mice were allowed to recover and the kidney bearing the islet graft was removed 2 days later for cryostat sections, and observed for fluorescent green signal by fluorescence microscopy.

Islet cell lysis, protein kinase assay and gel quantification Islet pellets were dislodged into cold lysis buffer $(20 \mathrm{mmol} / \mathrm{l}$ Tris-acetate, $\mathrm{pH} 7.0,0.27 \mathrm{~mol} / 1$ sucrose, $1 \mathrm{mmol} / 1$ EDTA, $1 \mathrm{mmol} / 1$ EGTA, $50 \mathrm{mmol} / 1$ sodium fluoride, $1 \%$ (vol/vol) Triton X-100, $10 \mathrm{mmol} / 1$ ß-glycerophosphate, $1 \mathrm{mmol} / 1$ dithiothreitol [DTT], $10 \mathrm{mmol} / \mathrm{l} p$-nitrophenylphosphate and antiproteases) and briefly sonicated prior to centrifugation. Total protein in cell lysates was quantified by the Bradford method (Bio-Rad Bioassay Kit; Bio-Rad Laboratories, Basel, Switzerland). Islet protein extracts $(40 \mu \mathrm{g})$ were incubated for $3 \mathrm{~h}$ at $4^{\circ} \mathrm{C}$ with $1 \mu \mathrm{g}$ of the fusion protein glutathione $S$-transferase (GST)-c-Jun coupled with glutathione beads. After centrifugation, the beads were washed twice and then resuspended in $20 \mu \mathrm{l}$ kinase buffer (20 mmol/1 HEPES, pH 7.5, 20 mmol/1 B-glycerophosphate, $10 \mathrm{mmol} / 1 \mathrm{MgCl}_{2}$ and $\left.1 \mathrm{mmol} / \mathrm{l} \mathrm{DTT}\right)$ and incubated with $1 \mu \mathrm{l}\left[\gamma_{-}{ }^{33} \mathrm{P}\right] \mathrm{ATP}\left(111 \times 10^{12} \mathrm{~Bq} / \mathrm{mmol}\right)$ (Amersham Biosciences, Little Chalfont, Bucks, UK) at $30^{\circ} \mathrm{C}$ for $30 \mathrm{~min}$. The reactions were terminated by addition of $2 \times$ Laemmli sample buffer $(125 \mathrm{mmol} / \mathrm{l}$ Tris- $\mathrm{HCl}, \mathrm{pH} 6.8,4 \%$ SDS, $100 \mathrm{mmol} / \mathrm{l} \mathrm{DTT}, 0.02 \%$ [wt/vol] Bromophenol Blue, $20 \%$ [ $\mathrm{vol} / \mathrm{vol}]$ glycerol) and samples were boiled for $5 \mathrm{~min}$. Phosphorylation of substrate proteins was examined after overnight exposure of polyacrylamide gels to autoradiography and quantifications were accomplished by Phosphor-Imager analysis (Molecular Imager FX; Bio-Rad Laboratories).

Measure of $m R N A$ expression by real-time RT-PCR Total RNA was extracted from isolated islets using a commercial Kit (RNeasy Mini-kit protocol; Qiagen, Hilden, Germany) and quantified by spectrophotometry. RNA was reverse transcribed to cDNA $\left(1 \mathrm{~h}\right.$ at $37^{\circ} \mathrm{C}$ and $10 \mathrm{~min}$ at $\left.95^{\circ} \mathrm{C}\right)$ using random primers (Gibco BRL Life Technologies). Aliquots of the generated cDNAs were used for gene amplifications. We applied a quantitative real-time RT-PCR technique to measure gene expressions; this method has been described in detail (see manufacturer's literature: Light Cycler; Roche Molecular Biochemicals). The PCR uses the following primers: rat $\mathrm{c}-f o s$, sense 5'-GCTGACAGATACGCTCCAAG-3', antisense 5'CCTAGATGATGCCGGAAACA-3'; human c-fos, sense 5'TGATACACTCCAAGCGGAGAC-3', antisense $5^{\prime}$-CC CAGTCTGCTGCATAGAAGG-3'; human tubulin, sense 5'-CCACGTTGGCCAGGCTGGTGTC-3', antisense 5'CTGTGATGAGTTGCTCAGGGTGG-3'; rat tubulin, sense 5'-GGAGGATGCTGCCAATAACT-3', antisense 5'GGTGGTGAGGATGGAATTGT-3'. The PCR products were further analysed by agarose gel electrophoresis to confirm the correct length of the amplified products.

Biological effects of D-JNKI Isolated human and rat islets (30 islets per well) were treated with increasing doses of DJNKI $(1,5,10,30$ and $50 \mu \mathrm{mol} / \mathrm{l})$ and cultured for 3 days at $37^{\circ} \mathrm{C}$. Islets toxicity was assessed by double staining nuclei of cells with propidium iodide (10 $\mu \mathrm{g} / \mathrm{ml})$ (Sigma Aldrich) and Hoechst $33342(25 \mu \mathrm{g} / \mathrm{ml})$ (Sigma Aldrich), and then observed under a fluorescence microscope.

Assessment of islet viability Rat islets (600 islets per well), treated or not with D-JNKI $(1 \mu \mathrm{mol} / \mathrm{l})$, were cultured for 2 days at $37^{\circ} \mathrm{C}$ and then exposed to continuous stimulation with IL-1 $\beta(10 \mathrm{ng} / \mathrm{ml})$ for 5 days. Islet cells were washed with PBS, collected by centrifugation and frozen prior to cryostat sections. Islet sections were processed for terminal deoxynucleotidyl transferase (TdT) dUTP nick end labelling (TUNEL) assay as described in the protocol (Apoptag Plus Peroxidase In Situ Apoptosis Detection Kit; Chemicon International, Billerica, MA, USA). Further, a part of the islet cells was trypsinised in trypsin-EDTA solution for $15 \mathrm{~min}$ at $37^{\circ} \mathrm{C}$ and apoptotic cells were visualised with Hoechst 33342 (as fragmented pycnotic blue-stained nuclei) and counted under the fluorescence microscope.

Statistical analysis All experiments were performed a minimum of three times with three different donors. All results are presented as means \pm SD. Statistical analysis for multiple comparisons was determined by Student's $t$ test or one-way ANOVA. The differences found between the experimental groups were statistically significant at $p<0.05$ or $p<0.01$.

\section{Results}

Cellular uptake of D-TAT-FITC peptide into isolated islets We previously showed that the D-JNKI peptide is able to enter beta cell lines in culture and thereby to protect them from IL-1 $\beta$-induced apoptosis by blocking the signalling events downstream of JNK [6]. Because rat and human pancreatic islets are condensed structures compared with monolayer-cultured cells, we investigated whether such a peptide could penetrate throughout the islet mass. To 
this end, we coupled an FITC-glycine group to the $\mathrm{NH}_{2}$ terminus of the ten amino acid transporter peptide derived from the human immunodeficiency (HIV)-TAT ${ }_{48-57}$ nuclear factor sequences. D-TAT-FITC peptide $(1 \mu \mathrm{mol} / \mathrm{l})$ was injected into the rat pancreatic duct prior to pancreatic tissue digestion. The fluorescent signal was immediately monitored at the end of the islet preparation, then isolated islets were cultured for additional times (24, 36 and $48 \mathrm{~h})$. Cellular uptake of D-TAT-FITC was efficient and still detected after 2 days of culture (Fig. 1a). No fluorescence was recorded in the islet control group treated or not with FITC, which provides evidence that fluorescein alone does not cross the cell membrane. In parallel, freshly isolated human islets were incubated with the labelled peptide and fluorescence signal was detected as previously (Fig. 1b). To determine the proficiency of the peptide to translocate into the core of the islets, transduction was assessed by confocal laser scanning microscopy of live non-fixed islets. Images were collected at different plans (z-position), showing the ability of D-TAT-FITC to transduce throughout the entire islet (Fig. 1c). In conclusion, the labelled peptide efficiently enters both human and rat islet cells and appears stable for up to 2 days of culture. We have also used D-JNKI-FITC; we were not able to document any differences in penetra- a

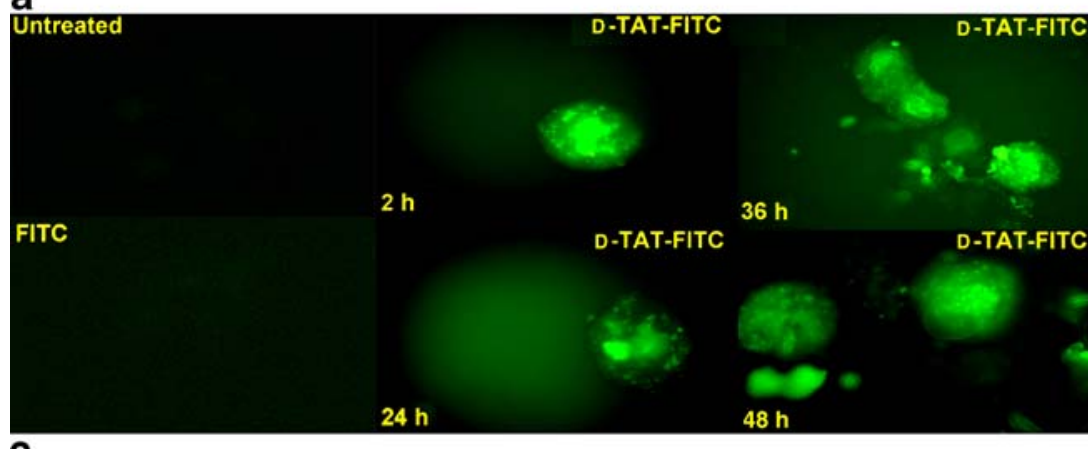

C
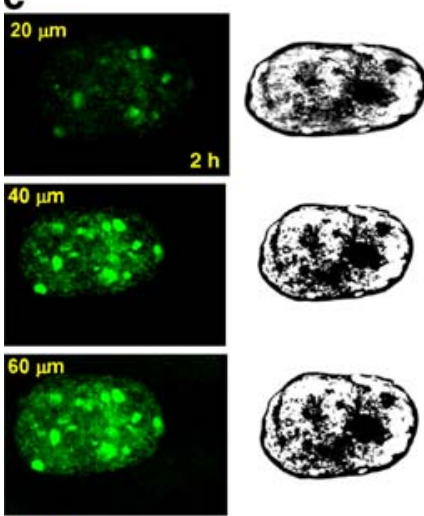

$80 \mu \mathrm{m}$
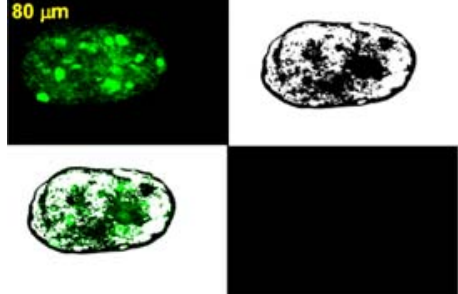

Fig. 1 Transduction of D-TAT-FITC into pancreatic islets. a D-TATFITC peptide $(1 \mu \mathrm{mol} / \mathrm{l})$ was injected into the rat pancreatic duct before pancreatic digestion and isolated islets were cultured for the indicated times $(24,36$ and $48 \mathrm{~h})$. Control islet groups represent isolated islets from FITC untreated (Untreated) or treated pancreas $(F I T C)$. b Fresh human islets were incubated with or without the DTAT-FITC peptide $(1 \mu \mathrm{mol} / 1)$ for the indicated times $(24,36$, and $48 \mathrm{~h}$ ). The control islet group (Untreated) represents untreated islets. Treated islets were washed and visualised under a fluorescence microscopy. c Transduction of D-TAT-FITC $(1 \mu \mathrm{mol} / \mathrm{l})$ was assessed by confocal laser scanning microscopy of live non-fixed rat islets b

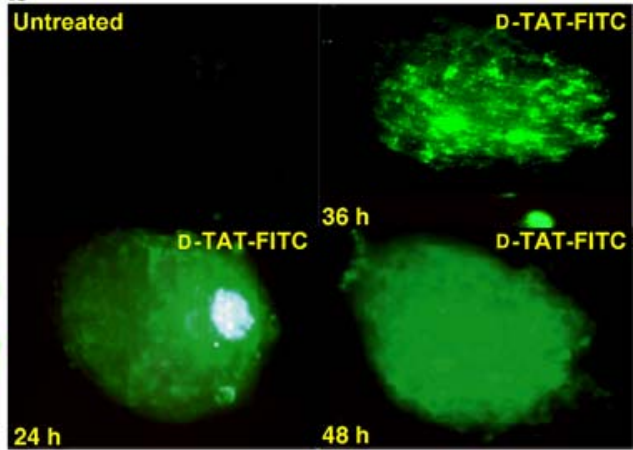

d
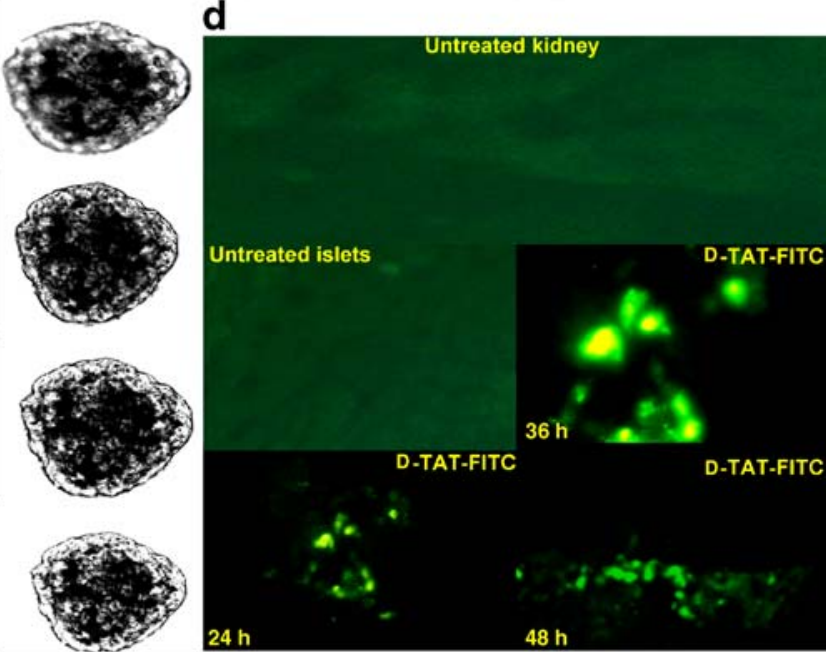

$24 \mathrm{~h}$

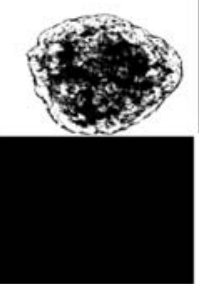

incubated for 2 days. Pictures were taken at different focal plans. Fluorescence was analysed by $N$-step-20 $\mu \mathrm{m}, z$-position sectional scanning of islets $(10 \times)$. Consecutive sections are shown. d Human islets were incubated for $1 \mathrm{~h}$ with or without the D-TAT-FITC peptide $(1 \mu \mathrm{mol} / \mathrm{l})$, and were transplanted under the left kidney capsule of nude mice. The kidney bearing the islet grafts was removed at the indicated times $(24,36$ and $48 \mathrm{~h})$ and was sectioned for morphological examination under a fluorescence microscope. Controls represent no grafted kidney tissue (Untreated kidney) or no treated islet graft (Untreated islets). Data are representative of three independent experiments 
tion and transduction efficiencies between D-TAT and DJNKI (data not shown).

D-TAT-FITC peptide remains stable inside islets in vivo We next investigated the stability of the D-TAT peptide molecule in a transplantation context (in vivo). Immediately after islet purification, isolated human islets were incubated with or without D-TAT-FITC $(1 \mu \mathrm{mol} / \mathrm{l})$, and then transplanted under the left kidney capsule of nude mice. The left kidney bearing the islet grafts was then removed from the animal body at different times (24, 36 and $48 \mathrm{~h}$ ), and cryostat tissue sections were processed and examined under the microscope. Tissue sections of the right kidney were used as control group to monitor the autofluorescence of the kidney tissue. D-TAT-FITC was observed as an intense fluorescent signal without detectable leakage in the examined kidneys bearing the islet grafts (Fig. 1d). This experiment demonstrates that the D-TAT peptide stably remains inside the treated islets (in vivo) for at least 2 days after transplantation.

Biological effects of D-JNKI on isolated pancreatic islets The inhibitor of JNK (D-JNKI), developed from the minimal conserved 20 amino acid sequence derived from the entire JNK binding domain $\left(\mathrm{JBD}_{1-280}\right)$ of islet brain-1 (IB1), was covalently linked to the D-TAT $48-57$ transporter [6]. To study the biological effects of D-JNKI, we first assessed the potential toxicity of D-JNKI on both rat and human pancreatic islets. To this end, rat and human pancreatic islets were incubated with or without D-JNKI $(1,5,10,30$ and $50 \mu \mathrm{mol} / \mathrm{l})$ for up to 3 days and were then stained with the fluorescent dyes propidium iodide and Hoechst 33342. The combination of both dyes allows differential staining of nuclei from dead cells (in red) from ones with an intact membrane (in blue) [13].

Islet viability was impaired in a concentration- and speciesdependent manner. At $1 \mu \mathrm{mol} / \mathrm{l}, \mathrm{D}-\mathrm{JNKI}$ appears not toxic in this assay on rat islets; above $5 \mu \mathrm{mol} / \mathrm{l}$, significant cell-death occurs (Fig. 2a). Compared with rat, human islets appear slightly more resistant with no apparent toxicity recorded at the concentration of $10 \mu \mathrm{mol} / \mathrm{l}$. However, human islet viability was affected when islets were treated with concentrations $>50 \mu \mathrm{mol} / 1$ (Fig. 2b). These data demonstrate that D-JNKI appears less toxic on human islets than on rat islets, which may allow testing of higher concentrations to achieve protective effects.

$D$-JNKI decreases JNK signalling during islet preparation and after IL-1 $\beta$ exposure To study the ability of D-JNKI to modulate the JNK signalling pathway during the islet isolation procedure and after cytokine exposure, isolated rat islets were treated with or without D-JNKI (from the digestion step), and incubated for 2 days. Cultured islets were then briefly exposed to the cytokine IL-1 $\beta$. Total protein extracts were prepared and JNK activity was measured by kinase assays using GST-c-Jun as substrate.
Fig. 2 Toxicity of D-JNKI on pancreatic islets. Isolated rat (a) and (b) human pancreatic islets were exposed to increasing concentrations of D-JNKI as indicated in a $(1,5,10 \mu \mathrm{mol} / \mathrm{l})$, and b $(1,5,10,30$ and $50 \mu \mathrm{mol} / 1)$ and incubated at $37^{\circ} \mathrm{C}$ for up to 3 days. Islets were double stained with the fluorescent dyes Hoechst and propidium iodide. Stained islets were visualised under a fluorescence microscope. Data are representative of four independent experiments

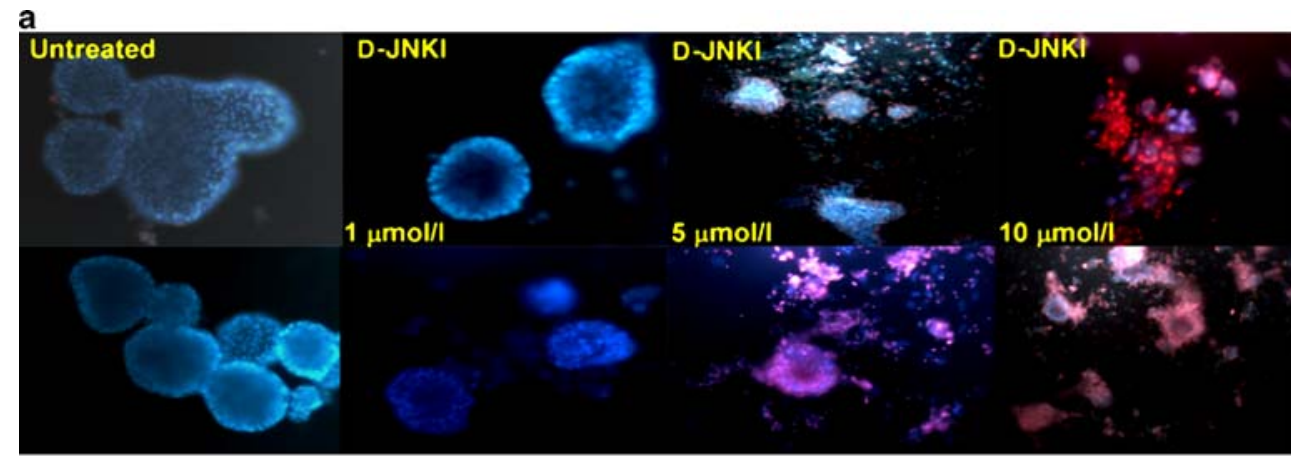

b

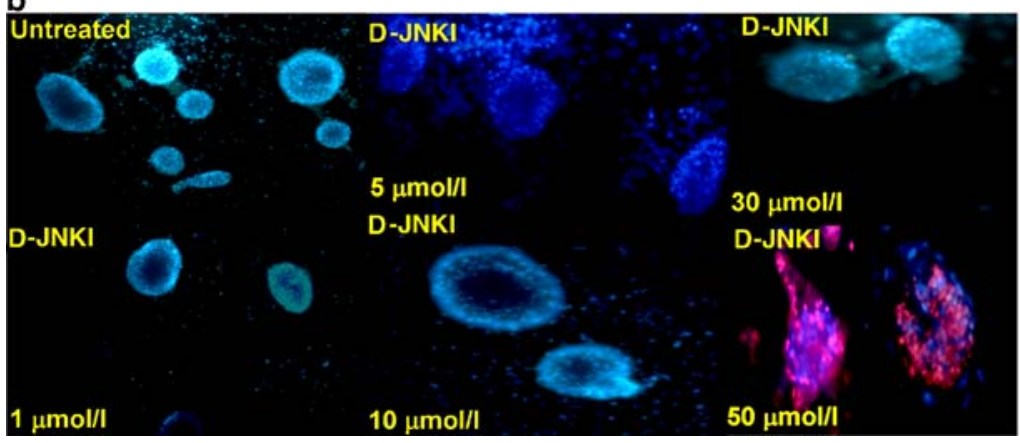




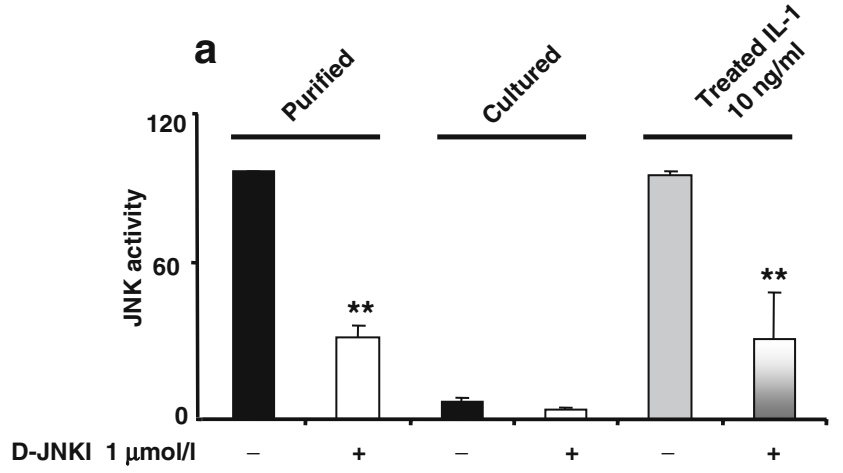

b

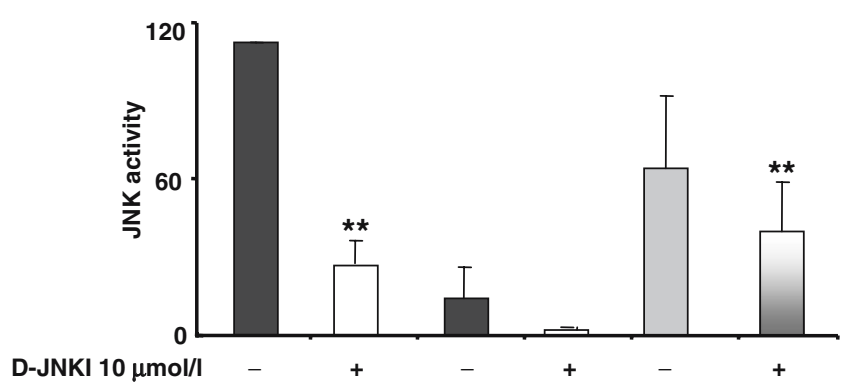

Fig. 3 D-JNKI efficiently prevents c-Jun phosphorylation in pancreatic islets. a Rat islets were treated with or without D-JNKI $(1 \mu \mathrm{mol} / \mathrm{l})$ (prior to pancreatic digestion), then purified islets were incubated for 2 days before a short stimulation $(45 \mathrm{~min})$ with $\mathrm{IL}-1 \beta(10 \mathrm{ng} / \mathrm{ml})$. Proteins were extracted and JNK activity was determined by kinase assay using GST-c-Jun as substrate. The reaction was incubated $30 \mathrm{~min}$ at $30^{\circ} \mathrm{C}$ in the presence of $\left[\gamma_{-}{ }^{33} \mathrm{P}\right]$ ATP and stopped by heating for $10 \mathrm{~min}$ in SDS sample buffer. Samples were resolved on $10 \%$ SDS-PAGE and gels were analysed by autoradiography. Protein phosphorylation was quantified by Phosphor-Imager. b Human islets were processed as described above for rat islets. Data shown are the mean of three independent experiments. $n=3$, means \pm SD. ${ }^{*} p<0.01$ for D-JNKI-treated vs untreated islets and for D-JNKI/IL-1 $\beta$ vs IL-1 $\beta$ islets

Activity of JNK was high after islet purification and declined to a low level over 2 days of culture, as previously reported [11] (Fig. 3a), and treatment of rat islets (prior isolation) with D-JNKI strongly (60\%) reduced JNK activity after purification. Short-term exposure of the cultured islets to IL-1 $\beta$ alone increased JNK activity to the same high level as during the isolation process. D-JNKI drastically reduced JNK activity ( $>50 \%$ ) (Fig. $3 \mathrm{a}$ ).

Similarly, we investigated the ability of D-JNKI to inhibit JNK activation after purification in human islets. Part of the purified islets treated with or without D-JNKI was cultured for 2 days and exposed to IL- $1 \beta$. JNK activity was assessed by kinase assay as described previously. These experiments indicated that D-JNKI used at $10 \mu \mathrm{mol} / \mathrm{l}$ (but not at $1 \mu \mathrm{mol} / \mathrm{l}$ ) reduced JNK phosphorylation of c-Jun in purified islets (Fig. 3b). IL-1 $\beta$ increased JNK activity (fourfold over untreated control), which was reduced in the D-JNKI-treated islet group. Of note, D-JNKI was less efficient in preventing JNK activation following cytokine stimulation despite the high peptide concentration used (Fig. 3b).

$D$-JNKI downregulates c-fos expression during rat islet preparation and after $I L-1 \beta$ exposure c-fos transcription is positively regulated by the JNK-target ELK1 transcription factor [14] and its expression was shown to be induced by IL-1 $\beta$ in pancreatic beta cells [15]; constitutive expression of the 280 amino acid JNK-inhibitory domain of IB1 in the $\beta$ TC-3 cell line decreases its expression [16]. To determine whether the cell-permeable peptide D-JNKI could interfere with JNK signalling in vivo, we measured its effect on the expression of c-fos in rat islets. Islets treated with or without D-JNKI (prior to pancreatic digestion) were cultured for 2 days and exposed to IL- $1 \beta$. Total RNA was extracted and reversed to cDNA. Quantification and normalisation to tubulin indicated that $\mathrm{c}$-fos mRNA is high in purified islets and reaches a low basal level after 2 days of culture (Fig. 4). Addition of D-JNKI reduced the expression of c-fos in the immediate post-isolation period in comparison with untreated islet controls (Fig. 4). Increased c-fos mRNA expression was also detected in rat islets exposed to IL-1 $\beta$ and a single addition of D-JNKI significantly reduced its expression level (Fig. 4). In rat islets, D-JNKI was more efficient in reducing c-fos mRNA after the purification process than after IL- $1 \beta$ stimulation despite an equal inhibition on JNK activity after both stresses (Fig. 3a). Further, addition of D-JNKI did not impair insulin secretion in pancreatic islets (data not shown).

D-JNKI partially protects from islet cell death D-JNKI was shown to block apoptosis of the insulin-secreting $\beta \mathrm{TC}-3$

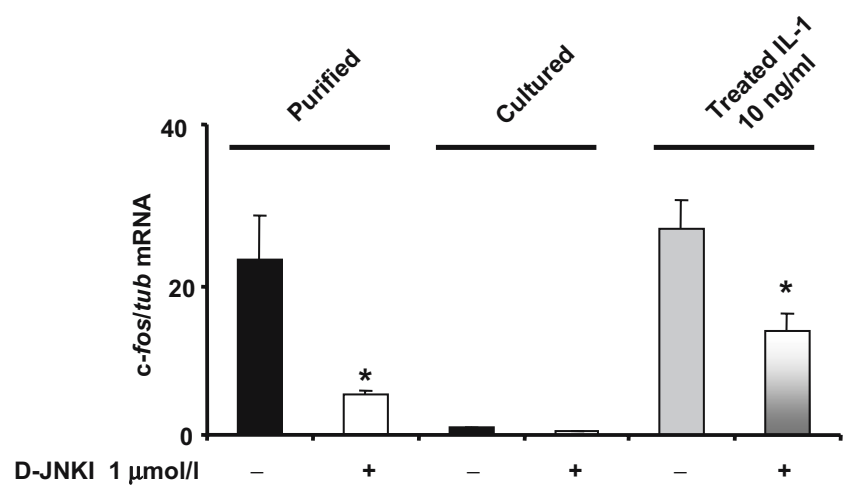

Fig. 4 D-JNKI downregulates c-fos expression in rat pancreatic islets. Rat pancreases were treated (prior to the digestion step) with or without D-JNKI $(1 \mu \mathrm{mol} / \mathrm{l})$ and the isolated islets were incubated for 2 days before being exposed for $45 \mathrm{~min}$ to IL-1 $\beta$ (10 $\mathrm{ng} / \mathrm{ml})$. No additional exposure to D-JNKI was performed after the initial treatment of the pancreas. Total RNA was extracted and mRNA quantification was evaluated by real-time PCR. Tubulin $(t u b)$ was used as a control for normalisation. The data are representative of three independent experiments. $n=3$, means $\pm \mathrm{SD}$. ${ }^{*} p<0.01$ for $\mathrm{D}$ JNKI-treated vs untreated islets and for treated D-JNKI/IL- $1 \beta$ vs IL$1 \beta$ islets 
cells in response to IL-1 $\beta$ stimulation [6]. To determine whether D-JNKI could protect rat islets from cytokineinduced islet apoptosis, pancreatic islets treated with or without D-JNKI (prior digestion step) were isolated and cultured for 2 days before being exposed to IL- $1 \beta$ for up to 5 days. Islet viability was assessed by staining islet cells with propidium iodide and Hoechst 33342, and morphological changes were visualised under the fluorescence microscopy (Fig. 5a). Islets apoptosis was further assessed by the TUNEL assay, which stains fragmented apoptotic nuclei brown in our assay (Fig. 5b).
A high level of islet cell apoptosis (determined by TUNEL assay), as well as morphological changes, was recorded after IL- $1 \beta$ exposure relative to unexposed controls (Fig. 5). The majority of the islet cells had lost their spherical and compact structure and debris was seen around the disintegrating islets compared with those of the control group without any apparent loss of structure (Fig. 5a).

The number of positive cells in the TUNEL assay was higher in the untreated purified islet groups and those exposed to IL- $1 \beta$ compared with the one treated with DJNKI (Fig. 5b). The per cent of apoptotic cells measured by
Fig. 5 D-JNKI protects against IL- $1 \beta$-induced cell destruction. a Rat islets were stained with both of the nuclear dyes Hoechst and propidium iodide and visualised under a fluorescence microscopy. b Rat pancreases were treated with or without DJNKI $(1 \mu \mathrm{mol} / 1)$ before the enzymatic digestion step. After purification, islets were cultured for 2 days, then collected by centrifugation and stored at $-80^{\circ} \mathrm{C}$. Frozen cell pellets were employed for cryostat sections. Some islets were exposed to continuous IL-1 $\beta$ stimulation $(10 \mathrm{ng} / \mathrm{ml})$ for 5 days. Apoptotic cells determined by TUNEL reaction were stained brown. c Islets were separated by trypsinEDTA and single cells were stained with Hoechst for scoring pycnotic nuclei. Data are representative of two independent experiments, each with two replicates, means \pm SD. ${ }^{*} p<0.01$ for D-JNKI/IL-1 $\beta$ - vs IL-1 $\beta$-treated islets a

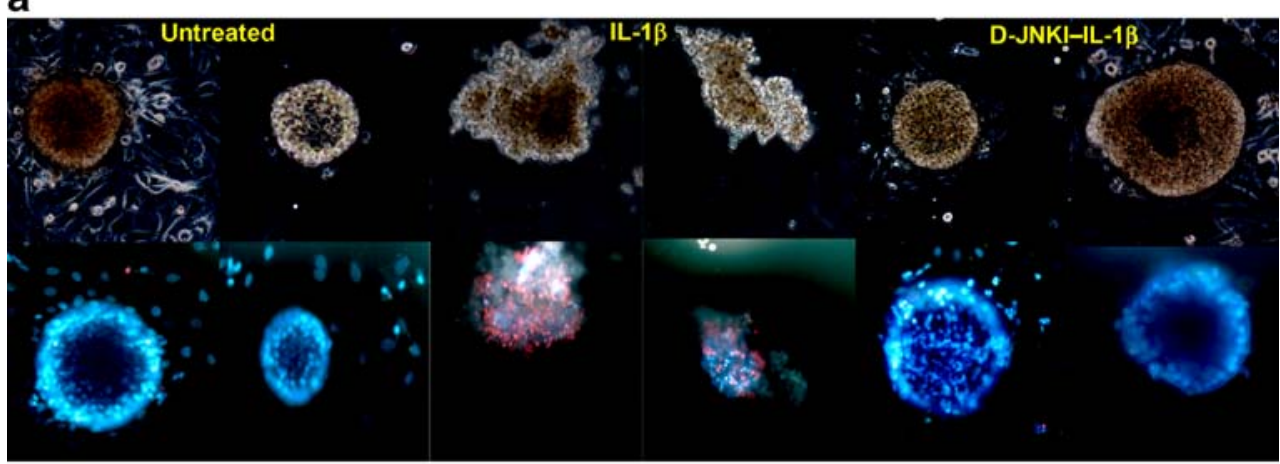

b
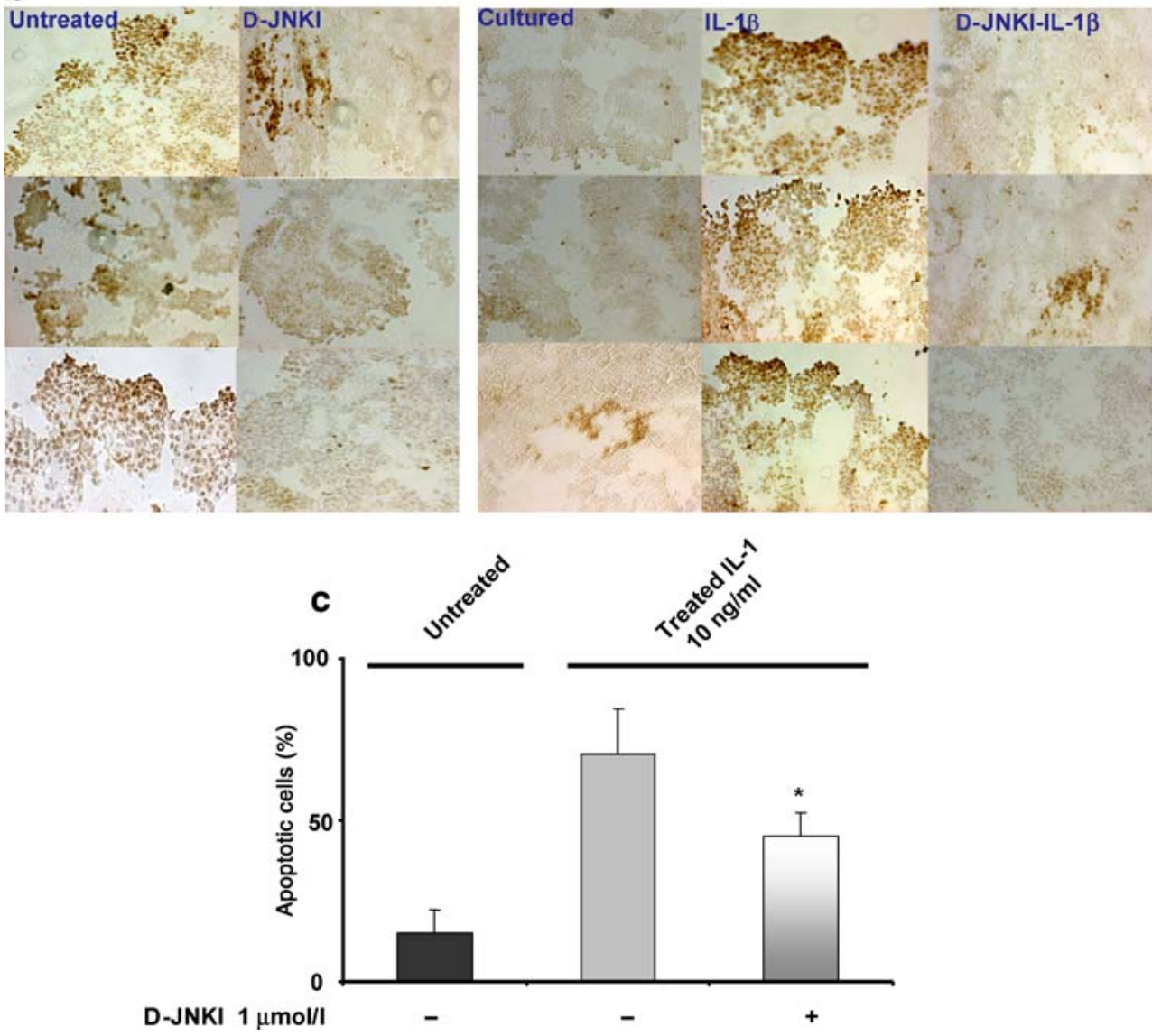
scoring pycnotic nuclei stained in blue also partially decreased in D-JNKI-treated islets (Fig. 5c).

\section{Discussion}

Several factors have been identified as causing islet death during isolation or shortly after transplantation. These include: exposure of islets to pro-inflammatory cytokines during transplantation that results in both immunological and non-immunological inflammatory responses [17]; damage caused by the isolation procedure itself including removal of the extracellular matrix, which increases the vulnerability of islets during clinical islet transplantation $[8$, 18]; and exposure to pro-inflammatory cytokines released by infiltrate cells (macrophages) shortly after transplantation that is recognised as being one mechanism that mediates primary non-function of the graft $[19,20]$.

The main common process of all these factors is the activation of apoptotic signalling pathways [21]. It is therefore of critical importance to understand the main pathways leading to islet death during the whole transplantation procedure in order to improve the efficiency of the process. In vitro studies have shown that cytokine-mediated beta cell apoptosis essentially involves the activation of the JNK and NF-KB signalling pathways $[6,22]$. JNK is also known to be activated in response to the islet isolation procedure itself $[11,23,24]$. Thus, the ability to manipulate the JNK signalling pathway may be crucial to the maintenance of a functioning islet cell graft by reducing apoptosis [24, 25]. Here, we demonstrated that the isolation process and IL-1 $\beta$ promote activation of JNK to a similar degree in both human and rat islets. We further report that inhibition of the JNK pathway by the cell-permeable inhibitor D-JNKI peptide prevents JNK activation in rat and human islets and suppresses the expression of the JNK nuclear target, c-fos mRNA. D-JNKI also improves viability after isolation and protects rat islets from IL-1 $\beta$ induced islet cell death while preserving insulin secretion (data not shown).

Our data indicate that JNK signalling contributes to the apoptotic response of islets. Others have previously demonstrated that additional pro-apoptotic pathways, including NF- $\mathrm{KB}$ and the $\mathrm{p} 38$ kinases, are likely players in beta cell death as well $[22,26]$. Therefore, we believe that activation of the JNK signalling pathway is likely to be a necessary, rather than a sufficient, event for the apoptotic response of islet cells after both isolation and cytokine stresses. Thus, optimal recovery of islets might require blockage of several pathways, including the ones mentioned above. Further experiments will be needed to test whether the addition of p38 or NF-KB inhibitors might enhance islet viability.
Ultimately, a cocktail of different apoptotic blockers might become of general use during the islet isolation-transplantation procedure.

JNK signalling controls the expression of immediate early genes such as the c-fos and c-Jun transcription factor family members $[6,27]$. One potential mechanism whereby JNK might control the beta cell death response could therefore be through transcriptional regulation. The role of c-fos in apoptosis was suggested in previous studies, especially those involving neuronal cells $[28,29]$. Blocking the JNK pathway in our studies decreased c-fos mRNA expression and correspondingly improved islet viability of IL-1 $\beta$-treated pancreatic rat islets. In contrast to the situation with rat islets, IL- $1 \beta$ exposure of human islets induced neither c-fos mRNA nor apoptosis, but addition of D-JNKI decreased c-fos mRNA after islet purification. However, promising data from other groups have also shown that JNK inhibition improves viability and function of human islets after grafting [24, 25]. This indicates that JNK plays a role in human islet death. Again, activation of p38 and NF- $\mathrm{kB}$ are probably the main pathways to block simultaneously with JNK to better help islets resist both the isolation and transplantation procedures.

Use of adenoviral vectors as a strategy for gene delivery is still associated with toxicity [30, 31], and the use of protein transduction domains derived from viral proteins to deliver protective molecules into cells is now well accepted for safer and more efficient delivery. Many protein transduction domains (PTDs) have been shown to cross biological membranes and to promote the delivery of peptides and protein molecules into diverse cell types [6, 32]. The most used PTDs are derived from the homeodomain transcription factor Antennapedia and the HIV transactivator TAT protein. Many studies have shown that the TAT transduction system is useful for the delivery of small peptide drugs in isolated pancreatic islets [33], and has been shown to be much more efficient than viral transduction [34]. The D-TAT peptide sequence is short (11 amino acids), has low apparent toxicity at the concentrations used here [34], and efficiently and rapidly crosses the cell membranes and promotes the delivery of small peptides into different pancreatic beta cells as determined by confocal experiments [6]. Its transduction seems independent of receptors and transporters. This independence from membrane receptors is highly advantageous for ex vivo delivery of proteins to islet cells. Further, when used in its D-form, TAT is highly resistant to proteolytic degradation and less immunogenic compared with the L-form [35].

We have described here the effective transduction of isolated rat and human pancreatic islets (ex vivo) in culture with the D-TAT peptide. Following grafting, delivery of the peptide appeared restricted to the grafts with no apparent 
leaking phenomenon 2 days after transplantation. This property is particularly relevant to achieve high local concentrations of potent anti-apoptotic drugs while minimising potentially detrimental side-effects on surrounding tissues. Finally, the system appeared to stably block JNK for at least 2 days. This feature might be absolutely necessary to optimally protect islets against the waves of attacks of the inflammatory reactions in the days following transplantation.

Acknowledgements This work was supported by Juvenile Diabetes Research Foundation International (JDRF) and the Swiss National Science Foundation (FNS).

Duality of interest The authors of this manuscript have no dualities of interest.

\section{References}

1. Barshes NR, Wyllie S, Goss JA (2005) Inflammation-mediated dysfunction and apoptosis in pancreatic islet transplantation: implications for intrahepatic grafts. J Leukoc Biol 77:587-597

2. Mandrup-Poulsen T (1996) The role of interleukin-1 in the pathogenesis of IDDM. Diabetologia 39:1005-1029

3. Riachy R, Vandewalle B, Kerr Conte J et al (2002) 1,25dihydroxyvitaminD3 protects RINm5F and human islets cells against cytokines-induced apoptosis implication of the antiapoptotic protein A20. Endocrinology 143:4809-4819

4. Mandrup-Poulsen T, Bendtzen K, Nerup J, Dinarello CA, Svenson M, Nielsen JH (1986) Affinity-purified human interleukin I is cytotoxic to isolated islets of Langerhans. Diabetologia 29:63-67

5. Eizirik DL, Mandrup-Poulsen T (2001) A choice of death-the signal-transduction of immune-mediated beta-cell apoptosis. Diabetologia 44:2115-2133

6. Bonny C, Oberson A, Negri S, Sauser C, Schorderet DF (2001) Cell-permeable peptide inhibitors of JNK: novel blockers of betacell death. Diabetes 50:77-82

7. Papaccio G, Graziano A, D'Aquino R, Valiante S, Naro F (2005) A biphasic role of nuclear transcription factor (NF)-kappaB in the islet beta-cell apoptosis induced by interleukin (IL)-1beta. J Cell Physiol 204:124-130

8. Paraskevas S, Maysinger D, Wang R, Duguid TP, Rosenberg L (2000) Cell loss in isolated human islets occurs by apoptosis. Pancreas 20:270-276

9. Shapiro AM, Lakey JR, Ryan EA et al (2000) Islet transplantation in seven patients with type 1 diabetes mellitus using a glucocorticoid-free immunosuppressive regimen. N Engl J Med 343:230238

10. Mellert J, Hering BJ, Liu X et al (1999) Critical islet mass for successful porcine islet autotransplantation. J Mol Med 77:126129

11. Abdelli S, Ansite J, Roduit R et al (2004) Intracellular stress signaling pathways activated during human islet preparation and following acute cytokine exposure. Diabetes 53:2815-2823

12. Ricordi C, Lacy PE, Finke EH, Olack BJ, Scharp DW (1988) Automated method for isolation of human pancreatic islets. Diabetes 37:413-420
13. Hoorens A, Van de Casteele M, Kloppel G, Pipeleers D (1996) Glucose promotes survival of rat pancreatic $\beta$-cells by activating synthesis of proteins which suppress a constitutive apoptotic program. J Clin Invest 98:1568-1574

14. Cavigelli M, Dolfi F, Claret FX, Karin M (1995) Induction of cfos expression through JNK mediated TCF/Elk phosphorylation. EMBO J 14:5957-5964

15. Kwon G, Corbett JA, McDaniel ML (1996) Interleukin-1-induced Fos and Jun do not regulate inducible nitric oxide synthase in rat islets of Langerhans and RINm5F cells. Endocrinology 137:825-830

16. Nikulina MA, Sandhu N, Shamim Z et al (2003) The JNK binding domain of islet-brain 1 inhibits IL-1 induced JNK activity and apoptosis but not the transcription of key proapoptotic or protective genes in insulin-secreting cell lines. Cytokine 24:13-24

17. Rother KI, Harlan DM (2004) Challenges facing islet transplantation for the treatment of type 1 diabetes mellitus. J Clin Invest 114:877-883

18. Davalli AM, Scaglia L, Zangen DH, Hollister J, Bonner-Weir S, Weir GC (1996) Vulnerability of islets in the immediate posttransplantation period: dynamic changes in structure and function. Diabetes 45:1161-1167

19. Vara E, Arias Diaz J, Garcia C et al (1995) Production of TNF alpha, IL-1, IL-6 and nitric oxide by isolated human islets. Transplant Proc 27:3367-3371

20. Ryan EA, Lakey JR, Rajotte RV et al (2001) Clinical outcomes and insulin secretion after islet transplantation with the Edmonton protocol. Diabetes 50:710-719

21. Mandrup-Poulsen T (2001) Beta-cell apoptosis: stimuli and signaling. Diabetes 50(Suppl 1):S58-S63

22. Rehman KK, Bertera S, Bottino R et al (2003) Protection of islets by in situ peptide-mediated transduction of the Ikappa B kinase inhibitor Nemo-binding domain peptide. J Biol Chem 2782:9862-9868

23. Paraskevas S, Aikin R, Maysinger D et al (1999) Activation and expression of ERK, JNK, and p38 MAP-kinases in isolated islets of Langerhans: implications for cultured islet survival. FEBS Lett 455:203-208

24. Aikin R, Maysinger D, Rosenberg L (2004) Cross-talk between phosphatidylinositol 3-kinase/AKT and c-Jun NH2-terminal kinase mediates survival of isolated human islets. Endocrinology 145:4522-4531

25. Noguchi H, Nakai Y, Matsumoto S et al (2005) Cell permeable peptide of JNK inhibitor prevents islet apoptosis immediately after isolation and improves islet graft function. Am $\mathrm{J}$ Transplant 5:1848-1855

26. Saldeen J, Lee JC, Welsh N (2001) Role of p38 mitogen-activated protein kinase (p38 MAPK) in cytokine-induced rat islet cell apoptosis. Biochem Pharmacol 61:1561-1569

27. Ventura JJ, Kennedy NJ, Lamb JA, Flavell RA, Davis RJ (2003) c-Jun $\mathrm{NH}(2)$-terminal kinase is essential for the regulation of AP1 by tumor necrosis factor. Mol Cell Biol 23:2871-2882

28. Zhang S, Liu J, MacGibbon G, Dragunow M, Cooper GJ (2002) Increased expression and activation of c-Jun contributes to human amylin-induced apoptosis in pancreatic islet beta-cells. J Mol Biol 324:271-285

29. Vyas S, Biguet NF, Michel PP et al (2002) Molecular mechanisms of neuronal cell death: implications for nuclear factors responding to cAMP and phorbol esters. Mol Cell Neurosci 21:1-14

30. Bowen GP, Borgland SL, Lam M, Libermann TA, Wong NC, Muruve DA (2002) Adenovirus vector-induced inflammation: capsid-dependent induction of the $\mathrm{C}-\mathrm{C}$ chemokine RANTES requires NF-kappa B. Hum Gene Ther 13:367-379

31. Zhang N, Schroppel B, Chen D et al (2003) Adenovirus transduction induces expression of multiple chemokines and chemokine receptors in murine beta cells and pancreatic islets. Am J Transplant 3:1230-1241 
32. Futaki S, Suzuki T, Ohashi W et al (2001) Arginine-rich peptides. An abundant source of membrane-permeable peptides having potential as carriers for intracellular protein delivery. J Biol Chem 276:5836-5840

33. Kaneto H, Nakatani Y, Miyatsuka T et al (2004) Possible novel therapy for diabetes with cell-permeable JNK-inhibitory peptide. Nat Med 19:1128-1132
34. Embury J, Klein D, Pileggi A et al (2001) Proteins linked to a protein transduction domain efficiently transduce pancreatic islets. Diabetes 50:1706-1713

35. Herve M, Maillere B, Mourier G, Texier C, Leroy S, Menez A (1997) On the immunogenic properties of retro-inverso peptides. Total retro-inversion of T-cell epitopes causes a loss of binding to MHC II molecules. Mol Immunol 34:157-163 